\title{
ИССЛЕДОВАНИЕ РАЗВИТИЯ РОССИЙСКОГО ЭКСПОРТА НА ОСНОВЕ ДАННЫХ ВНЕШНЕЭКОНОМИЧЕСКОЙ СТАТИСТИКИ
}

\author{
(c) 2021 Круглов Вадим Сергеевич \\ кандидат экономических наук, доцент, доцент кафедры экономики и таможенного дела \\ Поволжский институт управления им. П.А. Столыпина РАНХиГС при Президенте РФ, Россия, Саратов \\ E-mail: kruglov885@gmail.com \\ (c) 2021 Ермилов Игорь Сергеевич \\ кандидат экономических наук, руководитель отдела внешнеэкономической деятельности \\ ООО «Мебельная фабрика «Мария», Россия, Саратов \\ E-mail: igorermilov@yandex.ru

\section{(c) 2021 Толмачев Михаил Николаевич} \\ доктор экономических наук, профессор Департамента бизнес-аналитики \\ Финансовый университет при Правительстве Российской Федерации, Россия, Москва \\ E-mail: MNTolmachev@fa.ru
}

В статье проведен анализ развития внешнеэкономической деятельности в РФ, ее влияния на экономику страны. Обобщен фактический и статистический материал, характеризующий место России в мировой торговле. Выявлены основные проблемы, которые сопровождают осуществление внешнеэкономической деятельности сегодня и предложены направления развития российского экспорта.

Ключевые слова: международная торговля, внешнеэкономическая деятельность, экспорт, импорт, таможенные платежи

Россия является частью мировой экономики. Мы участвуем во всех международных экономических процессах: экспорт, импорт, международная кооперация и других. Наша внешняя торговля стабильно растет. Мы много продукции экспортируем, много продукции ввозим из-за рубежа. И это несмотря на так называемые санкции и «торговые войны».

За последние 20 лет наши внешнеторговые отношения с остальным миром увеличились в 4 раза (рис. 1). Более того, внешнеэкономическая деятельность давно уже стала стабильным источником поступления денег в российский бюджет.

Каждый год, торгуя в среднем на 600 миллиардов долларов, мы получаем в бюджет около 70 миллиардов долларов таможенных платежей. Были годы, когда половина доходной части нашего бюджета формировалась от таможенных платежей. Сегодня эта цифра меньше.

Особое значение имеет экспортная деятельность. В российском внешнеторговом обороте экспорт занимает около 60 процентов (рис. 2). Наша экономика является экспортоориентиро- ванной. Вопросы укрепления экспортного потенциала России являются исключительно важными на современном этапе. Это неоднократно подчеркивал в Посланиях Федеральному собранию Президент Российской Федерации.

Более того, сегодня принят и реализуется национальный проект по развитию российского экспорта - «Международная кооперация и экспорт».

Итак, внешняя торговля растет, мы активно торгуем с другими странами. Но имеются проблемы. Что мы поставляем на мировой рынок? Нефть, газ и мало обработанные продукты. Доля подобной продукции в структуре экспорта в некоторые годы доходила до 70 процентов. Такая структура экспорта нам досталась из 90-х годов.

Сегодня мы экспортируем готовой продукции в 15 раз меньше Китая, в 5 раз меньше Южной Кореи. И в целом, по общим объемам экспорта мы сильно уступаем ведущим странам мира (рис. 3).

Сегодня начался новый период в мировой экономике. Появилось множество проблем внешней торговли. Они напрямую касаются

* Статья подготовлена по результатам исследований, выполненных за счет бюджетных средств по государственному заданию Финансового университета 


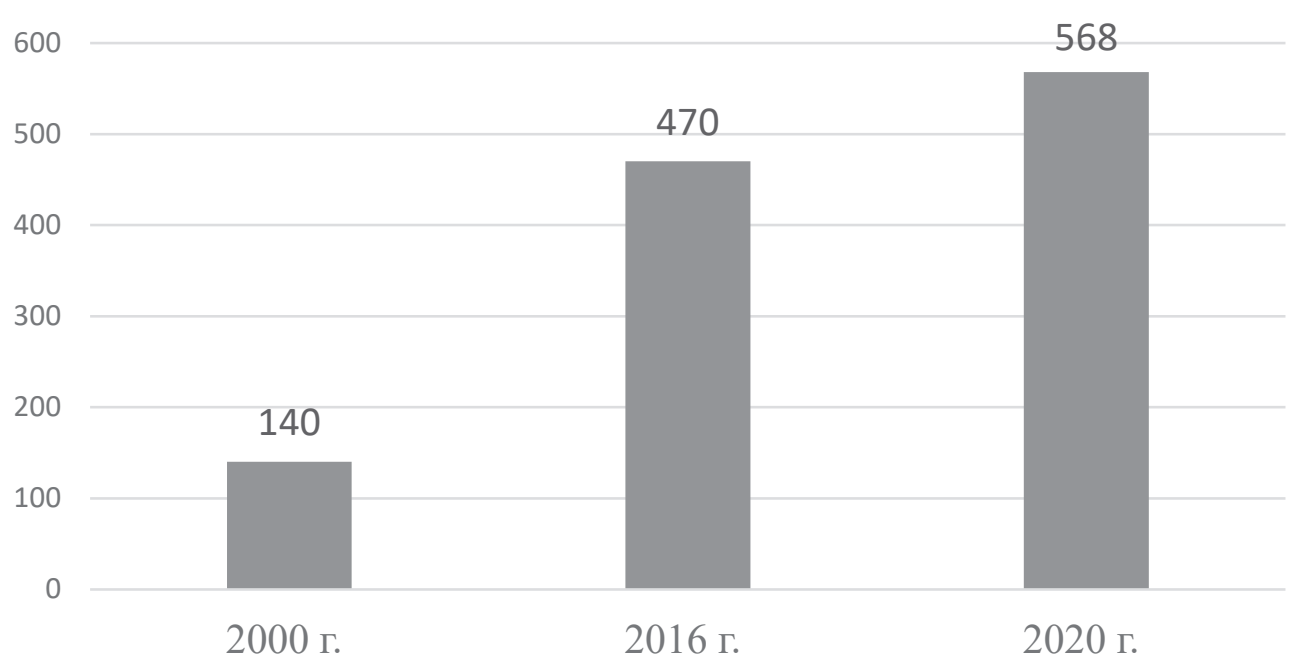

Puc. 1. Темпы роста внешней торговли РФ, млрд. дол

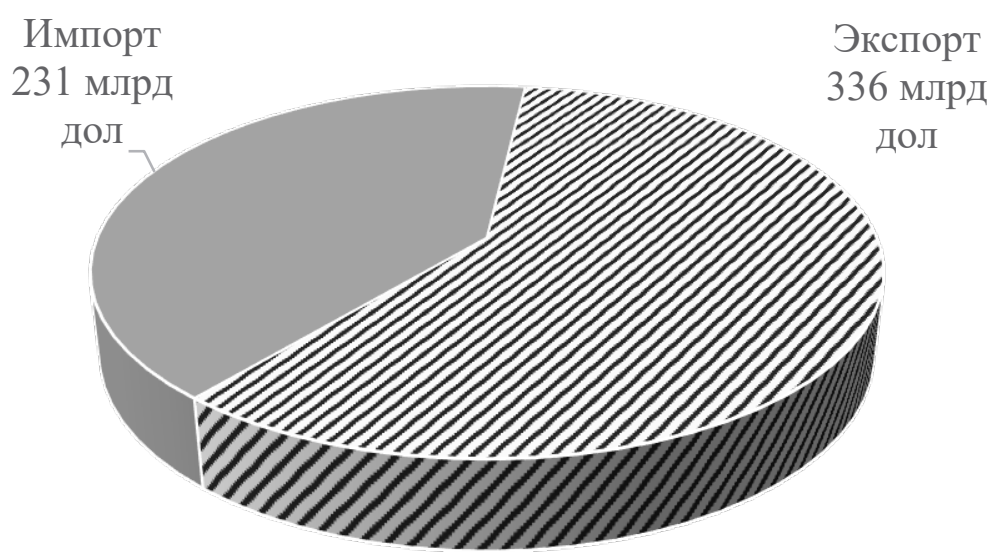

Puc. 2. Роль экспорта во внешнеэкономической деятельности РФ (данные за 2020 год)

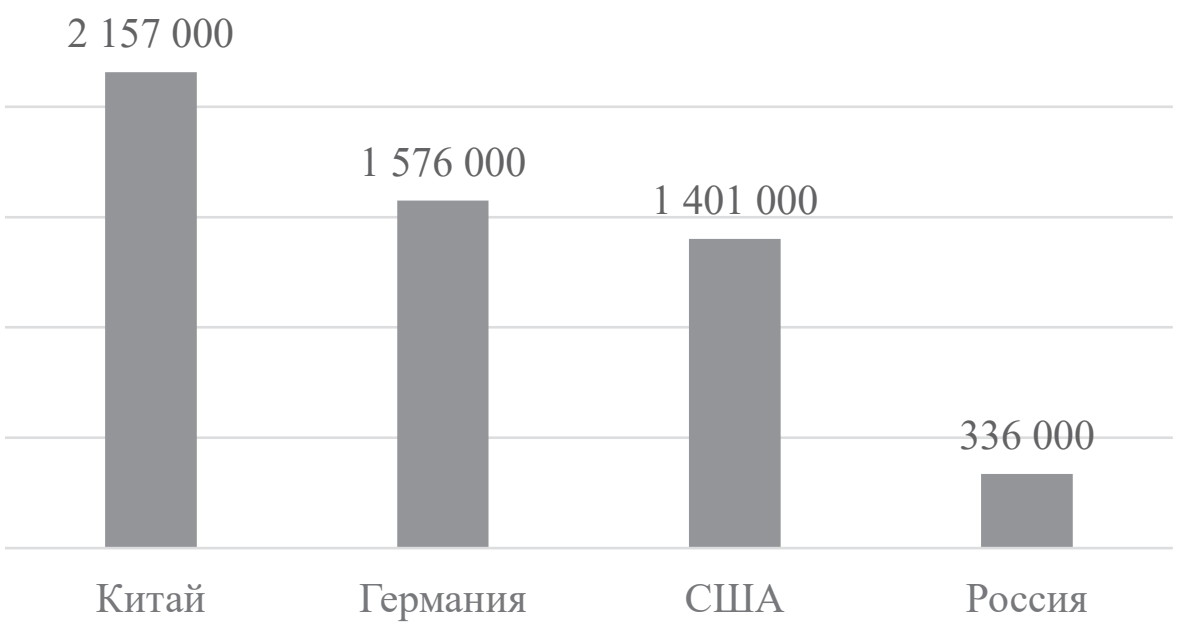

Puc. 3. Доля разных стран в мировой торговле (экспорт, млн. дол) 
экономики России. Нам приходится жить и работать с учетом этих проблем.

Не вдаваясь в подробности, можно выделить главное:

1. Всемирная торговая организация (ВТО) сегодня не отвечает всем запросам участников мировой экономики. Более того, ВТО стала проамериканской организацией. Эти претензии уже звучали много раз.

2. Использование западными странами политического давления и экономических санкций против Российской Федерации.

3. Разворот большинства западных стран от глобализации к национальному протекционизму.

4. Торговые войны.

Говоря о развитии экспорта, необходимо отметить, что сегодня, несмотря на кратковременное снижение объемов в 2019-2020 годах, экспортные поставки российской продукции за рубеж довольно значительные, более того, в РФ созданы максимально комфортные условия для осуществления экспортной деятельности.

Можно выделить следующие, благоприятствующие развитию российского экспорта, факторы:

- ориентация государства на поддержку российского экспорта;

- создание федеральной сети центров поддержки экспорта под эгидой Российского экспортного центра (РЭЦ);

- организация таможенной системы РФ по мировым стандартам;

- цифровизация структуры российских таможенных органов и оформление основного потока таможенных деклараций в цифровом формате в Центрах электронного декларирования (ЦЭД);

- создание приоритетного порядка таможенного оформления российских экспортных поставок (в среднем время выпуска таможенной декларации при экспорте не превышает 1 часа);

- полная цифровизация таможенной процедуры экспорта: внедрение процессов авторегистрации таможенных деклараций и автовыпуска экспортных грузов.

По данным таможенной внешнеторговой статистики, экспорт России составил в 2020 году 336 миллиардов долларов и снизился по сравнению с 2019 годом на 88 миллиарда долларов или на 21 процент (рис. 4).

Очевидна положительная динамика экспорта на протяжении последних двадцати лет. Ис- ключения составляют годы, приходящиеся на мировой экономический кризис 2008 года и на начало «санкционного периода» 2014 года. Тем не менее, очевидно налаживание ситуации в данной сфере.

Более того, за последние 20 лет стоимостные объемы российского экспорта увеличились почти в 5 раз.

Основу российского экспорта традиционно составляли топливно-энергетические товары (рис. 5). Тем не менее, их удельный вес в товарной структуре экспорта в 2020 году снизился и составил 50 процентов (в 2019 году - 62 процента).

Доля экспорта несырьевых неэнергетических товаров в общем объеме экспорта России в 2020 году составила 48 процентов (в 2019 году 36 процентов).

Важность экспорта в российской экономике очевидна, об этом говорят данные анализа, показывающего баланс экспорта/импорта в экономике РФ (см. рис. 2). Очевидно, что в среднем на экспорт приходится более 60 процентов всего внешнеторгового оборота России. Это высокий показатель, свидетельствующий об экспортоориентированности страны.

Несмотря на колебания, российский экспорт показывает положительную динамику. Можно сделать прогноз развития экспорта. Он положительный. Структура экспорта становится более совершенной. Снижается доля сырья и повышается доля готовой продукции.

Сегодня формируются новые основы международного разделения труда, меняются контуры мировой экономики. В последние годы мы сталкиваемся с новыми вызовами экономической среды. Учитывая вовлеченность экономики страны в мирохозяйственные процессы, требуется разработка эффективных мер и механизмов стимулирования и развития российского экспорта.

Как перспективные направления развития российского экспорта мы выделяем:

- увеличение экспорта несырьевой продукции;

- увеличение экспорта продукции машиностроения;

- увеличение экспорта российских услуг (медицинские услуги, экспорт образования, транспортные услуги и др.);

- увеличение количества малых и средних предприятий (МСП), вовлеченных в экспортную деятельность. 


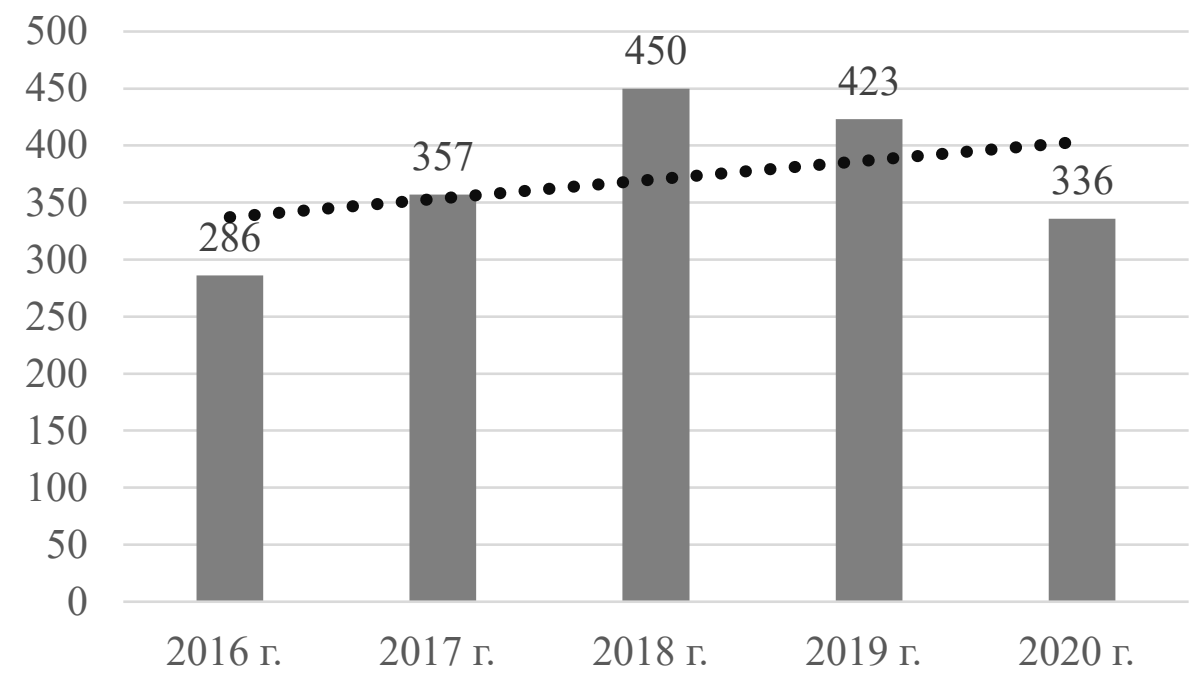

Puc. 4. Изменения объемов российского экспорта, млрд. дол

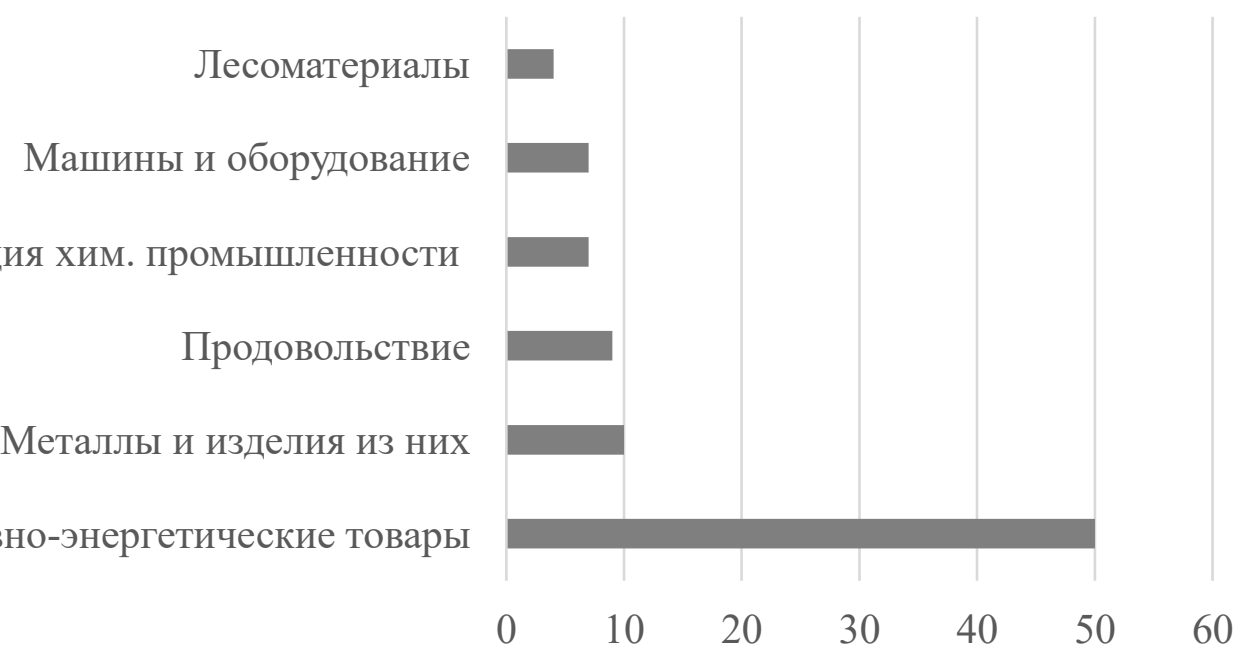

Puc. 5. Товарная структура российского экспорта в 2020 году, \%

Конечно мало обозначить только направления развития. Должен быть предложен механизм развития экспорта и конкретные мероприятия. Только в таком случае можно рассчитывать на развитие российского экспорта.

Какие меры можно предложить для развития экспорта?

Некоторые из них уже работают и используются экспортерами: возврат экспортного НДС и нулевые ставки экспортных пошлин на готовую продукцию.

Но есть новые меры поддержки экспорта, это:

1. Деятельность Российского экспортного центра и сети центров поддержки экспорта в регионах.
Оказывается, различная поддержка российским экспортерам: осуществляется информационная и консультационная поддержка; проводятся бизнес-миссии российских производителей за рубежом, либо приглашаются в страну потенциальные покупатели перспективной российской продукции (реверсная бизнесмиссия); организовывается и субсидируется участие российских производителей в международных выставках. В отдельных случаях может оплачиваться часть транспортных затрат для российских экспортеров.

Тем не менее существует проблема - не все экспортеры пользуются предоставляемыми возможностями, многие даже не знают о них, несмотря на активную деятельность Российского 
экспортного центра и сети центров поддержки экспорта в регионах.

2. Таможенное стимулирование российских экспортеров (рис. 6).

Сегодня ситуация такова, что таможенные органы должны соответствовать новым условиям мировой экономики, ориентированной на глобальное внедрение IT-технологий.

Сегодняшние ориентиры для российской таможенной службы это:

1. Полномасштабная цифровизация и автоматизация деятельности.

2. Применение самообучающейся интеллектуальной Системы Управления Рисками при контроле внешнеэкономических поставок (СУР).

3. Организация таможенного контроля с использованием методов искусственного интеллекта и обработки больших данных (Big Data).

4. Содействие развитию российского экспорта. Поддержка российских предприятий- экспортеров и российских производителей. Вывод их на внешний рынок. Для это таможенные органы действуют совместно с Российским экспортным центром.

5. Обеспечение прозрачности совершения таможенных операций и проведения таможенного контроля.

6. Улучшение условий ведения предпринимательской деятельности и инвестиционного климата в стране.

7. Создание конкурентных преимуществ для добросовестных участников внешнеэкономической деятельности.

В таможенной части перечень документов, необходимых для экспорта сокращен до минимума. А сами экспортные поставки оформляются в приоритетном порядке. В том числе по автовыпуску.

Экспортная процедура сегодня полностью оцифрована (рис. 7). Перечень документов и

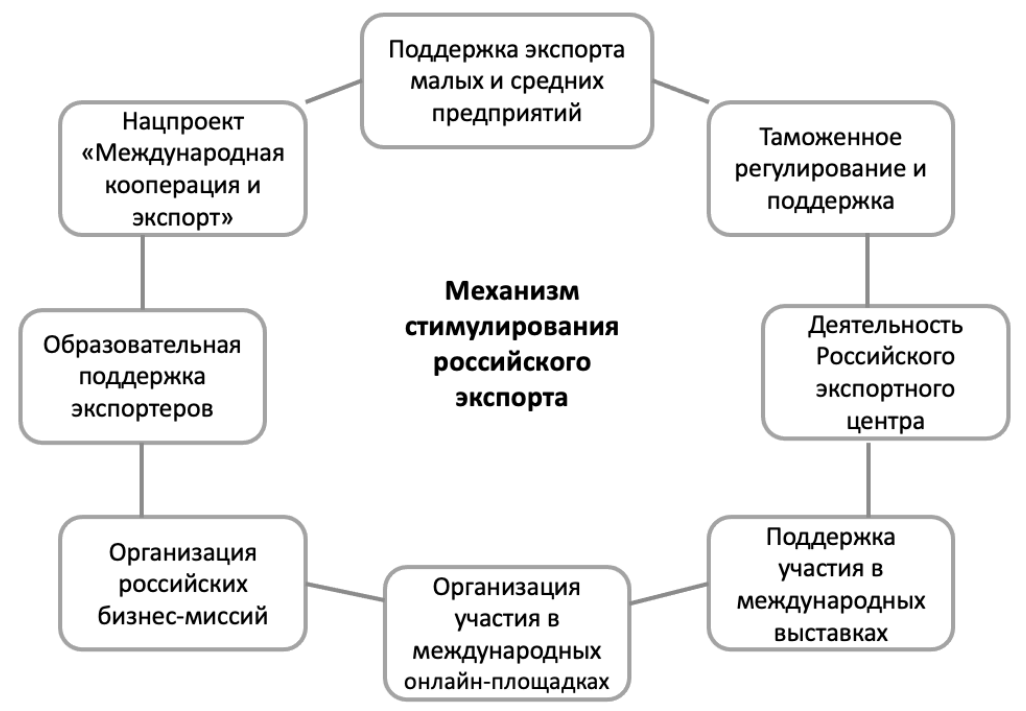

Puc. 6. Механизм таможенного стимулирования российского экспорта

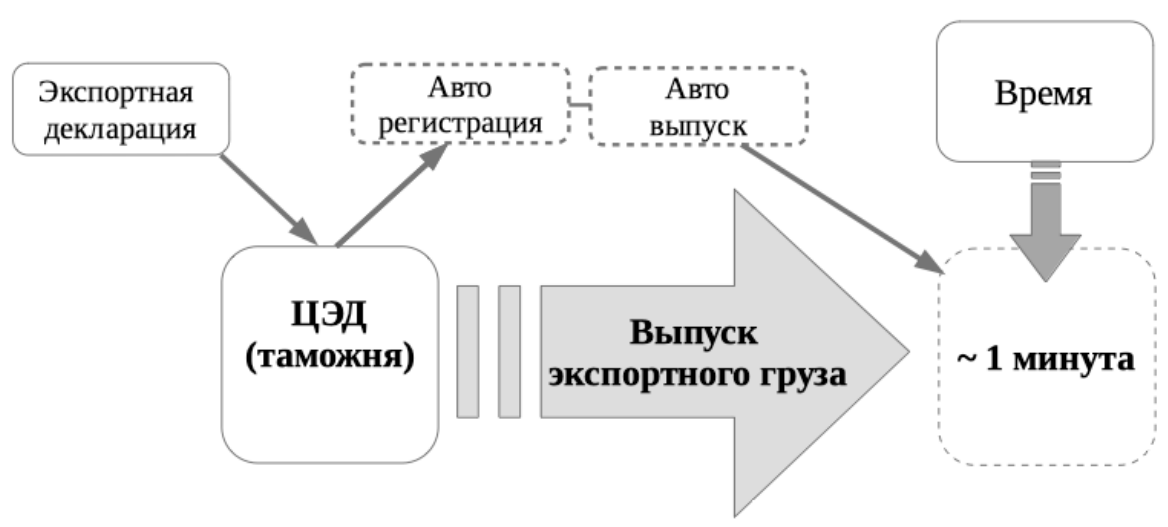

Рис. 7. Цифровизация таможенной процедуры «Экспорт» 
действий для реализации таможенной процедуры «Экспорт» сокращен до минимума.

Скорость таможенного оформления экспортной поставки может достигать 1 минуты (в случае автовыпуска).

На сегодняшний день около 70\% экспортных деклараций проходят процедуру автовыпуска. T.e., поданная экспортером в таможенные органы декларация на вывозимый товар проверяется и выпускается полностью в автоматическом режиме, без участия инспектора.

Основным принципом взаимоотношений между таможенными органами и декларантами и участниками ВЭД сегодня это упрощение таможенных формальностей и процедур, ускорение внешнеторгового оборота.

Сегодня декларанты работают в абсолютно новых, эффективных условиях. Выпуск таможней грузов происходит в течение полутора часа. А по некоторым поставкам он составляет от 2-х до 10-ти минут. Введены абсолютно новые понятия, такие как автоматическая регистрация и автоматический выпуск таможенных деклараций. Выпуск около 40\% таможенных деклараций происходит без участия инспектора таможни, в автоматическом режиме.

\section{Библиографический список}

1. Международная кооперация и экспорт: Паспорт национального проекта (программы). URL: http:// government.ru/info/35564/.

2. Послание Президента Федеральному собранию. URL: http://kremlin.ru/events/president/news/56957.

3. Таможенная служба Российской Федерации в 2020 году: Справочные материалы к расширенному заседанию коллегии ФТС РФ. URL: https://customs.gov.ru/activity/results/ezhegodnyj-sbornik-tamozhennayasluzhba-rossijskoj-federaczii.

4. Алехина О.В., Игнатева Г. В., Смирнова И.А. Цифровая таможня: прошлое, настоящее, будущее. // Вестник Саратовского государственного социально-экономического университета. 2019. № 3 (77). С. 9-14.

5. Baldwin R. (2020). The greater trade collapse of 2020: Learnings from the 2008-09 great trade collapse. VoxEU, April 07. URL: https://voxeu.org/article/greater-trade-collapse-2020 (дата обращения: 18.06.2021).

6. Official site of the World Bank. URL: https://data.worldbank.org/ (дата обращения 12.08.2021).

7. Official site of the World Trade Organization. URL: https://www.wto.org/ (дата обращения 12.08.2021).

8. Sforza A., Steininger M. (2020). Globalization in the time of Covid-19. CESifo Working Paper No. 8184, May, Munich, $52 \mathrm{p}$.

9. UNCTAD. Trade and Development Report 2019. URL: https://unctad.org/webflyer/trade-and-developmentreport-2019.

10. WTO. International Trade and Tariff Data. URL: https://data.wto.org. 